V. 1 - $\mathrm{N}^{\circ} 01$ - Ano 2021

ISSN: 2763-5724 | https://www.periodicojs.com.br/index.php/hs

\title{
REVIEW ON THE GENETIC, BEHAVIORAL AND SOCIAL INCLUSION PARAMETERS OF CHILDREN AND YOUNG PEOPLE WITH AUTISM AND TAEs
}

\author{
Mônica dos Santos Lins ${ }^{1}$ \\ Evandro Gomes da Silva Júnior ${ }^{2}$ \\ Fernanda Milleanny Santos Cirilo ${ }^{3}$ \\ Janderson dos Santos Araújo ${ }^{4}$ \\ Ana Laura da Silva Bila ${ }^{5}$
}

\begin{abstract}
There are different types of behavioral disorders of a genetic nature that affect human beings, among these we can mention the autism spectrum disorders (ASDs). O ASD is a disorder where its carriers tend to have difficulties in social interaction, repetitive and impulsive behaviors, many times it is violent, also showing many difficulties to develop activities that are constantly practiced easily by other children, VAZ
\end{abstract}

out a systematic review of items most correlated to behavioral, nutritional and et al (2015). This form several methodologies are being developed for the inclusion of children carrying two disorders in schools of basic education, both as adults in institutions of higher education, since this inclusion will guarantee a better quality of life, as discussed in our work. SILVA (2009). The objective of this work was to carry genetic aspects, apart from the conditions of inclusion of two individuals with ASD. In order to obtain the aforementioned objective, we have searched for papers that address these aspects, as well as means of social inclusion of children, young people and adults with Autism Spectrum Disorder (ASD). During the days of searches carried out by the team, and a careful selection by means of reading abstracts and complete reading papers, we had a total of 20 papers, being only selected 6 jobs at the end. The collected results show that ASDs are caused by genetic hazards and that the problems about the behavioral conditions and inclusion had decrease a little by means of the

\footnotetext{
${ }^{1}$ Graduando em Psicologia na Faculdade Três Marias - FTM

${ }^{2}$ Bacharelado em Ciências Biológicas pela Universidade Federal da Paraíba e mestrado em Desenvolvimento e Meio Ambiente pela Universidade Federal da Paraíba

${ }^{3}$ Graduando em Psicologia na Faculdade Três Marias - FTM

${ }^{4}$ Graduando em Psicologia na Faculdade Três Marias - FTM

${ }^{5}$ Graduando em Nutrição na Faculdade Três Marias - FTM
} 
advancement of science and improvement of techniques over a period years.

Keywords: ASD; advancement of science; inclusion; prejudices

\section{INTRODUÇÃO}

Há diversos tipos de transtornos comportamentais de caráter genético que atingem o ser humano, dentre estes podemos citar os transtornos de espectro do autismo (TEAs). Segundo GRUPTA e STATE (2006) o autismo e os TEAs possuem as mais fortes evidências de terem bases genéticas, ainda que a busca dos genes específicos que contribuem para essas síndromes de desenvolvimento, que são frequentemente devastadoras, tenha se mostrado extraordinariamente difícil. Em estudos com base numa análise do sequenciamento genético de 35.000 pessoas autistas e familiares, pesquisadores identificaram 102 genes como sendo os principais relacionados ao Transtorno do Espectro do Autismo (TEA). O número anterior, de 2015, era de 65 genes relevantes. Vale destacar que, se considerarmos todos os genes relacionados ao autismo, com todos os graus de importância, em 2020, temos um total de 913 genes reportados WRIGHT (2020).
O TEA é um transtorno onde seus portadores tendem a ter dificuldades na interação social, comportamentos repetitivos e impulsivos, muitas vezes até violentos apresentando, também, muitas dificuldades para desenvolver atividades que constantemente são praticadas facilmente por outras crianças, VAZ et al (2015). Desta forma várias metodologias foram, e estão sendo desenvolvidas para a inclusão de crianças portadoras dos transtornos nas escolas de ensino básico, bem como de adultos em instituições de ensino superior, visto que esta inclusão não só garantirá uma melhor qualidade de vida, mas também sua inserção em um mercado de trabalho permitindo-lhes o reconhecimento com cidadãos funcionais e produtivos de uma sociedade, como discutido nos trabalhos de SILVA (2009), RODRIGUES; MOREIRA E LERNER (2012). Segundo MENDES (2006), a partir do momento em que a política de inclusão passou a ser coerente com uma sociedade democrática, a inclusão escolar tornou-se parte fundamental da política governamental para manutenção do estado democrático. Outro ponto importante para que haja uma condição de inclusão efetiva é a relação nutricional, ou seja, o comportamento alimentar de crianças e adolescentes 
como visto no trabalho de FERNANDES

et al (2016), que no cotidiano de trabalho

no Centro Integrado de Educação

Especial da cidade de Teresina, Piauí, na hora do lanche, foram observados as mais variadas reações como recusa ou preferência por certa cor, cheiro, consistência e textura. Resistência a sentar à mesa para comer com outras pessoas, entrar no refeitório e aceitar preparações novas. O objetivo do presente trabalho foi realizar uma revisão sistemática de artigos mais correlacionando os aspectos comportamentais, nutricionais e genéticos, além das condições de inclusão dos indivíduos com TEA. Para tanto, forma pesquisadas as seguintes bases de dados: Lilacs, BVS (Biblioteca virtual de Saúde), MEDLINE-Bireme, ScieSearch e SciELO.

\section{MATERIAIS E MÉTODOS}

Para a obtenção do objetivo supracitado, primordialmente foram realizadas buscas de artigos que abordassem os aspectos genéticos, nutricionais, comportamentais, bem como meios de inclusão social de crianças, jovens e adultos portadores de autismo e Transtornos de Espectro do Autismo (TEAs). Os principais mecanismos de busca usados pelos pesquisadores foram Lilacs, BVS (Biblioteca virtual de Saúde), MEDLINE-Bireme, ScieSearch, SciELO e Google Acadêmico. Diante das buscas realizadas pela equipe, foram obtidos vários resultados e após criteriosa seleção por meio de leitura dos abstracts e leitura completa dos artigos atingiu-se um total de 20 artigos, dos quais foram selecionados apenas 6 .

\section{RESULTADOS}

Tabela 01. Relação dos estudos correlacionados com inclusão social e econômica, bem como dos fatores genéticos e alimentares associados ao comportamento de jovens e crianças portadores de TEAs.

\begin{tabular}{|c|c|c|}
\hline AUTOR/ANO & OBJETIVOS & PRINCIPAIS ACHADOS \\
\hline $\begin{array}{l}\text { Grupta et al. } \\
(2006)\end{array}$ & $\begin{array}{l}\text { Revisar a literatura resumindo os resultados de } \\
\text { estudos de ligação genética, citogenéticos e de } \\
\text { genes candidatos com um foco no progresso } \\
\text { recente. Além de considerar as vias promissoras } \\
\text { para pesquisas futuras. }\end{array}$ & $\begin{array}{l}\text { A revisão mostrou que a } \\
\text { identificação de alelos de risco ou } \\
\text { mutações de causas raras é somente } \\
\text { um importante passo para } \\
\text { desvendar a biologia dos TEAs e é } \\
\text { um esforço que irá requerer as } \\
\text { contribuições combinadas de uma } \\
\text { variedade de áreas, incluindo }\end{array}$ \\
\hline
\end{tabular}


V. 1 - $\mathrm{N}^{\circ} 01$ - Ano 2021

ISSN: 2763-5724 | https://www.periodicojs.com.br/index.php/hs

\begin{tabular}{|c|c|c|}
\hline & & $\begin{array}{l}\text { geneticistas, pesquisadores } \\
\text { clínicos, neurobiólogos do } \\
\text { desenvolvimento e profissionais de } \\
\text { neuro imagem. }\end{array}$ \\
\hline Wright. (2020) & $\begin{array}{l}\text { Analisar o genoma humano e indicar possíveis } \\
\text { indícios de variantes de risco de autismo nas } \\
\text { regiões } \\
\text { entre genes. }\end{array}$ & $\begin{array}{l}\text { O número dos principais genes do } \\
\text { autismo aumentou de } 65 \text { para } 102 \text {, } \\
\text { com base em uma análise de mais } \\
\text { de } \\
35.000 \text { encencias. } \\
\text { pesquisadores naram } \\
\text { evidências de que as variantes nas } \\
\text { chamadas "regiões não } \\
\text { codificantes" podem aumentar } \\
\text { risco de autismo. }\end{array}$ \\
\hline $\begin{array}{l}\text { Silva \& } \\
\text { Brotherhood. } \\
(2009)\end{array}$ & $\begin{array}{l}\text { Levantar dados sobre o processo de inclusão no } \\
\text { Brasil e no exterior, e fazer as devidas relações; } \\
\text { identificar as causas que dificultam sua } \\
\text { realização e investigar o conhecimento e a } \\
\text { postura do professor quanto autismo. Assim } \\
\text { como também o conhecer o posicionamento de } \\
\text { professores em formação em relação ao } \\
\text { assunto. }\end{array}$ & $\begin{array}{l}\text { O estudo mostrou que a inclusão } \\
\text { escolar é ainda um assunto que gera } \\
\text { muitas discussões e dúvidas no } \\
\text { meio acadêmico e junto aos } \\
\text { profissionais da educação. Os } \\
\text { acadêmicos são quase que } \\
\text { unânimes contra o processo de } \\
\text { inclusão das pessoas com } \\
\text { deficiência em classes do ensino } \\
\text { regular. }\end{array}$ \\
\hline $\begin{array}{l}\text { Rodrigues et } \\
\text { al. (2012) }\end{array}$ & $\begin{array}{l}\text { Compreender quais são as concepções dos } \\
\text { professores da rede pública sobre os alunos } \\
\text { diagnosticados como portadores de TGD ou } \\
\text { autismo no ensino regular e que posições } \\
\text { assumem perante os alunos com base em tais } \\
\text { concepções. }\end{array}$ & $\begin{array}{l}\text { Os resultados mostraram que a } \\
\text { inclusão escolar é um importante } \\
\text { dispositivo para a organização de } \\
\text { uma rede social que sustente a } \\
\text { autonomia de crianças com graves } \\
\text { transtornos, entretanto, as } \\
\text { dificuldades que os alunos que não } \\
\text { se encaixam na norma representam } \\
\text { impossibilitam a realização do } \\
\text { trabalho das professoras. }\end{array}$ \\
\hline $\begin{array}{l}\text { Cupertino et al. } \\
\text { (2018) }\end{array}$ & $\begin{array}{l}\text { Revisar sistematicamente os estudos sobre } \\
\text { distúrbios alimentares e do trato gastrointestinal } \\
\text { apresentado pelo indivíduo portador do TEA, a } \\
\text { fim de compreender como o comportamento }\end{array}$ & $\begin{array}{l}\text { Os estudos mostraram um quadro } \\
\text { de desequilíbrio. Foram } \\
\text { encontradas, também, alterações na } \\
\text { barreira de muco e permeabilidade }\end{array}$ \\
\hline
\end{tabular}




\begin{tabular}{|c|c|c|}
\hline & $\begin{array}{l}\text { alimentar influência na etiopatogênese e } \\
\text { manifestações clínicas da doença, com foco no } \\
\text { eixo intestino-cérebro. }\end{array}$ & $\begin{array}{l}\text { intestinal e alterações em proteínas } \\
\text { envolvidas na digestão e absorção } \\
\text { de alimentos. Dietas restritivas e a } \\
\text { modulação da microbiota, com uso } \\
\text { de probióticos e de antibióticos } \\
\text { específicos, são apresentadas como } \\
\text { estratégias terapêuticas } \\
\text { promissoras. Entretanto, não sendo } \\
\text { certo se alterações intestinais são } \\
\text { causa ou consequência das } \\
\text { alterações neurológicas } \\
\text { comunidade científica não tem } \\
\text { conclusões suficientes para indicar } \\
\text { o uso de dietas restritivas, e uso de } \\
\text { probióticos e de antibióticos como } \\
\text { terapêutica para o TEA. }\end{array}$ \\
\hline $\begin{array}{l}\text { Vaz et al. } \\
(2015)\end{array}$ & $\begin{array}{l}\text { Verificar o uso das dietas sem glúten e sem } \\
\text { caseína como parte do tratamento terapêutico } \\
\text { em portadores de Transtornos do Espectro } \\
\text { Autista. }\end{array}$ & $\begin{array}{l}\text { De acordo com os estudos } \\
\text { realizados, em nenhum artigo } \\
\text { analisado encontrou-se alguma } \\
\text { evidência conclusiva a respeito do } \\
\text { uso da dieta SGSC. Embora } \\
\text { utilizando diferentes metodologias } \\
\text { a pequena quantidade de estudos } \\
\text { dificulta a análise dos dados. }\end{array}$ \\
\hline
\end{tabular}

\section{CONSIDERAÇÕES FINAIS}

Os resultados coletados mostram que os TEAs são provocados por fatores genéticos e que ao longo dos anos, com o avanço da ciência, os métodos de aperfeiçoamento de técnicas para um melhor tratamento com a finalidade de melhorar as condições comportamentais e consequentemente de inclusão social cada vez melhor. Entretanto, são dados que ainda requerem maior discussão e amostragens mais substanciais para uma conclusão mais concreta.

5.

REFERÊNCIAS

\section{BIBLIOGRÁFICAS}

CARVALHEIRA, Gianna; VERGANI, Naja; BRUNONI, Décio. Genética do autismo. Rev. Bras. Psiquiatr, São Paulo, vol. 26, n. 4, São Paulo, dez. 2004. Disponível em: 
https://www.scielo.br/scielo.php?script= sci_arttext\&pid=S1516-

$44462004000400012 \& \operatorname{lng}=$ pt\&nrm=iso \&tlng=pt.

COSTA, Maria Ione Ferreira da; NUNESMAIA, Henrique Gil da Silva. Diagnóstico genético e clínico do autismo infantil. Arquivos de Neuropsiquiatria, São Paulo, vol. 56, n.1, p. 24-31, mar. 1998. Disponível em: https://www.scielo.br/scielo.php?script= sci_arttext\&pid=S0004282X1998000100004\&lng=en\&nrm=is o.

GUPTA, Abha R.; STATE, Matthew W. Autismo: genética. Rev. Bras. Psiquiatr, São Paulo, vol. 28, suppl. 1, p. S29-38, mai. 2006. Disponível em: https://www.scielo.br/scielo.php?script= sci_arttext\&pid=S151644462006000500005. Acesso em: 19 out. 2020 .

THOMAS, Marie-Claude. Introdução para uma genealogia do autismo. Tempo Psicanalítico. Tradução: José Durval Cavalcanti de Albuquerque. Rio de Janeiro, vol. 45, n. 2, p. 339-366, dez. 2013. Disponível em: http://pepsic.bvsalud.org/scielo.php?scri pt=sci_arttext\&pid=S010148382013000200007.

LIMA, Stéfanie Melo; LAPLANE, Adriana Lia Friszman de. Escolarização de Alunos com Autismo/ Schooling of
Students with Autism. Rev. bras. educ. espec; 22(2): 269-284, tab, graf.

Disponível

em: https://www.scielo.br/scielo.php?sc $\underline{\text { ript}}=$ sci_arttext\&pid=S1413-

$\underline{65382016000200269}$

SCHMIDT, Carlo; NUNES, Débora Regina de Paula; PEREIRA, Débora Mara; OLIVEIRA, Vivian Fátima de; NUERNBERG, Adriano Henrique; KUBASKI, Cristiane. Inclusão escolar e autismo: uma análise da percepção docente e práticas pedagógicas. Psicol. teor. prát; 18(1): 222-235, abr. 2016.

LEMOS, Emellyne Lima de Medeiros Dias; NUNES, Laísy de Lima; SALOMÃO, Nádia Maria Ribeiro. Transtorno do Espectro Autista e Interações Escolares: Sala de Aula e Pátio. Rev. bras. educ. espec; 26(1): 6984, jan.-mar. 2020.

WRIGHT, Jessica. Spectrum | Autism Research News https://www.spectrumnews.org NEWS Analysis of sequences pegs 102 top autism genes, 2020.

.RODRIGUES, Isabel de Barros; MOREIRA, Luiz Eduardo de V.; LERNER, Rogério. Análise institucional do discurso de professores de alunos diagnosticados como autistas em inclusão escola Universidade de São Paulo, São Paulo - SP - Brasil 
Psicologia: teoria e prática, v. 14, n. 1, p. 70-83, 2012.

CUPERTINO, Marli do Carmo; RESENDE, Michely Baptistele; VELOSO, Isabela de Freitas; CARVALHO, Camila Abreu de; DUARTE, Vitor Ferreira; RAMOS, Guilherme Alves. Transtorno do espectro autista: uma revisão sistemática sobre aspectos nutricionais e eixo intestino-cérebro ABCS Health Sci.; 44(2):120-130 Arquivos Brasileiros de Ciências da Saúde, 2019.

VAZ, Carolina Suemi Yabiku; AOKI, Kamila; FREITAS, Lylian; GOBATO, Amanda Oliva. Dieta sem glúten e sem caseína no Transtorno do Espectro Autista. CuidArte, Enferm; 9(1): 92-98, jan.-jun.2015.

SILVA, Rosângela Nunes Almeida da; CARVALHO FILHA, Francidalma Soares Sousa; LIMA, Ava Fabian dos Anjos; SILVA, Francisco Laurindo da; VILANOVA, Jaiane de Melo; SANTOS, Elzimar Palhano dos. Avaliação da qualidade de vida de crianças que estão no espectro do autismo. Rev. enferm. UFPE on line; 11(9): 3461-3470, set.2017.

SILVA, Maria do Carmo Bezerra de Lima; BROTHERHOOD, Rachel de Maya. AUTISMO E INCLUSÃO: DA TEORIA À PRÁTICA. V EPCC Encontro Internacional de Produção
Científica Cesumar 27 a 30 de outubro de 2009 